\title{
EXPERIMENTAL STUDY ON THE WORKING AND MECHANICAL PROPERTIES OF HIGH PERFORMANCE CEMENTITIOUS STRUCTURAL GROUTS
}

\begin{abstract}
By using the experimental study method, the working properties and mechanical properties of grouting materials were determined by changing the cement-sand ratio, water-cement ratio, and cement admixtures. The main factors affecting the properties of grouting materials and the mutual influence rules of various factors are analysed and determined, and the best value range is obtained. Finally, the compressive strength of 28-day ordinary Portland cement structure grouting is optimised to 50-80 MPa. Based on the grouting ratio of ordinary Portland cement, an experimental study on the early strength structure paste of sulphate aluminate cement was carried out. The paste with one day strength as high as $70 \mathrm{MPa}$ and good compatibility was prepared, and the early strength change law of the optimum ratio was deduced.
\end{abstract}

Keywords: cementitious structural grout, cement-sand ratio, water-cement ratio, workability, mechanical properties

\section{Introduction}

With the rise of the domestic reinforcement industry, convenience, efficiency, safety, and durability have become several essential criteria for the selection of reinforcement materials, and the various characteristics of high performance cement-based structural grout can meet the requirements of short duration, ease of construction, and safety and durability of structural reinforcement. With the rapid development of structural reinforcement engineering, grout is gradually applied to the field of support, such as beam, plate, column, wall reinforcement, mass foundation repair grouting, and so on, which has a good effect on practical engineering reinforcement. This kind of grout is called structural grout. With the further improvement of the grouting performance of high-performance cement-based structures, its application fields will be more extensive [1-9].

Many researchers in this field have made a lot of meaningful achievements in the development of high-performance cement-based grouting materials. Anagnostopoulos compared polycarboxylate superplasticiser (PCE) with polynaphthalene superplasticiser (SNF). Experiments were carried out with different doses of superplasticiser to study the effect of superplasticiser on ultra-fine or conventional cement-based grouting. He believes

\footnotetext{
${ }^{1}$ Chengdu Textile College, Chengdu, 610039, China, email: 87660164@qq.com, ORCID: 0000-0001-8875-2896

2 School of Architecture and Civil Engineering, Xihua University, Chengdu 610039 China, email: 0720090008@mail.xhu.edu.cn

*Corresponding author: 0720090008@mail.xhu.edu.cn
} 
that superplasticiser can improve the fluidity of cement-based grouting material, and the grouting with PCE has higher viscosity and increases the leakage rate and setting time of cement-based grouting material [10]. Mohammad et al. optimised cement-based grouting material by using bentonite, sodium silicate, sodium carbonate and air-entraining material TEA as chemical additives, and obtained that the content of sodium silicate was $2 \%$, and the optimum content of sodium carbonate was $3 \%$ [11]. Mahmood et al. proved through experiments that $0.16 \%$ polycarboxylic acid superplasticiser (PCE) polymer can reduce the weight loss rate of cement paste at $80{ }^{\circ} \mathrm{C}$, resulting in a sharp increase in apparent and plastic viscosity and a significant increase in compressive strength [12]. In Lin's et al. work, he mentioned that the cement mixture with polycarboxylate superplasticisers has better dispersibility and enhances the compressive strength of concrete than the viscous mixture of traditional comb polycarbonate superplastics [13]. Ahmed proposed that polycarbon benzoate can improve the workability better than polyphenylene propylene sulphonate (PNS). The use of polycarbonates can reduce viscosity and production pressure. These concrete have good durability in the potential external environment [14]. High-performance cement-based materials can be designed through mature theory and industry standardization, but there are too many variables that affect the performance of high-performance cement-based materials. Therefore, it is of certain guiding significance to obtain the design mix ratio of high-performance concrete in the case of short time and low cost.

\section{Test program}

Based on the theoretical ratio of the densest filling, the basic ratio range (Table 1) is designed as the basis for the performance test of cement-based grouting materials. In the course of the experiment, we adjust the type or dosage of the main components such as cement-sand ratio and water-cement ratio and keep the dosage of some parts unchanged.

Table 1

Proportioning parameters of the baseline cementitious grouts for the tests

\begin{tabular}{|c|c|c|c|c|c|c|}
\hline \multirow{2}{*}{ Items } & \multirow{2}{*}{ Grit ratio } & \multirow{2}{*}{$\begin{array}{c}\text { Water to } \\
\text { glue ratio }\end{array}$} & $\mathbf{N F}$ & $\mathbf{A S}$ & $\begin{array}{c}\text { NF+AS } \\
\text { Mixture }\end{array}$ & $\begin{array}{c}\text { Expansion agent as } \\
\text { a proportion of } \\
\text { cementitious materia }\end{array}$ \\
\cline { 4 - 6 } & & {$[-]$} & {$[\%]$} & {$[\%]$} & {$[\%]$} & {$[\%]$} \\
\hline Unit & {$[-]$} & $1.2-2$ & $0.6-0.8$ & 1 & $4-12$ \\
\hline Value & $1: 1.5-1: 1$ & $0.25-0.35$ & &
\end{tabular}

NF: naphthalene-formaldehyde superplasticiser, $\mathrm{N}$ for Naphthalene and $\mathrm{F}$ for Formaldehyde; AS: amino-sulphonate superplasticizer, A for Amino and S for Sulphonate; NF + AS Mixture: The content of the two components is $0.5 \%$ each

The working performance of the slurry mixture ratio and the change of mechanical properties after hardening were determined, and the interaction relationship was established [15]. Under the condition of keeping the basic parameters unchanged, the admixture of a single component is adjusted, or its type is changed according to the specific law to investigate the effect of component type and admixture on the performance of cement-based grouting material [16]. Through the analysis of the test results, the basic slurry mix ratio is optimised, and finally, the ideal mix ratio of high-performance cement-based paste is obtained. All experiments were carried out at room temperature of $20 \pm 5{ }^{\circ} \mathrm{C}$. 


\section{Effect of cement-sand ratio on the workability and mechanical properties of structural grout}

Different cement-sand ratios greatly influence the properties of high-performance cement-based structural slurry, especially on the mechanical properties after hardening. In order to prepare high-performance cement-based structural grouting material, we must first ensure its good workability and high strength. To ensure that the above requirements are met, it is necessary to ensure that the mortar has a sufficient amount of cement paste. The amount of cement paste required depends on the porosity between the sand and the total surface area. If it is a more negligible porosity and a smaller total surface area, the amount of cement paste required can be reduced. However, for the fine aggregate with large porosity and surface area, if the quantity of cement paste is insufficient, the performance of the mixture will be difficult to guarantee. Because the mortar does not contain coarse aggregate, the excessive amount of cement will lead to extreme shrinkage of the battery, leading to the mortar cracking [17].

The fineness modulus and particle gradation of sand affect the performance of mortar. When the fineness modulus of sand is higher, a relatively high impermeability pressure can be obtained. The smaller the fineness modulus of sand is, the more particles are, the larger the total surface area is, and the higher the void ratio is, the more adsorbed water is needed on the particle surface, and the more cement paste is needed between the particles. Therefore, more unit water is required in order to meet the flow conditions. However, as a result, the cement slurry is less used to bond and wrap the gaps between sand particles. As a result, there is a lack of bonding materials between fine aggregate particles, which reduces the bonding performance between particles and reduces the compatibility of fresh mortar. At the same time, the cement slurry cannot fill the gap between the particles completely, which is easy to produce pores and affect the mechanical properties of the slurry.

It can be seen from Table 2 that the flow rate has a general upward trend with the increase of the gelling ratio due to the influence of the working performance of the gelling slurry. This is because the remaining slurry is increasing, and the density decreases gradually after stirring the slurry at the same volume.

Table 2

Effect of cement to sand ratio on the workability of cementitious grouts

\begin{tabular}{|c|c|c|c|c|c|c|}
\hline \multirow{2}{*}{ Items } & \multirow{2}{*}{ Grit ratio } & \multicolumn{3}{|c|}{ Mobility } & \multirow{2}{*}{ Wet density } & \multirow{2}{*}{ Harmony } \\
\cline { 2 - 6 } & & Initial & $\mathbf{3 0}$ min later & Losses & & {$[-]$} \\
\hline Unit & {$[-]$} & {$[\mathbf{m m}]$} & {$[\mathbf{m m}]$} & {$[\mathbf{m m}]$} & {$\left[\mathbf{k g} / \mathbf{m}^{3}\right]$} & Sticky \\
\hline \multirow{4}{*}{ Value } & $1 / 1.5$ & 243 & 129 & 114 & 2396 & Sticky \\
\cline { 2 - 6 } & $1 / 1.4$ & 259 & 140 & 119 & 2389 & Good \\
\cline { 2 - 6 } & $1 / 1.3$ & 305 & 219 & 86 & 2253 & Good \\
\cline { 2 - 6 } & $1 / 1.2$ & 300 & 260 & 40 & 2214 & Good \\
\cline { 2 - 6 } & $1 / 1.1$ & 294 & 242 & 52 & 2180 & Lightly divorced \\
\cline { 2 - 6 } & $1 / 1$ & 327 & 270 & 57 & 2154 & \\
\hline
\end{tabular}

The initial flow rate varies slightly from $1 / 1.3$ to $1 / 1.1$, which means that the gelation ratio has little effect on the flow rate in this range. However, with the increase of gelling ratio, the flow loss decreases at first and then increases. Under the condition that the water-cement percentage and the amount of superplasticiser are constant, when the content 
of quartz sand increases, the flow characteristics of the slurry become weaker. With the rise of cement content, the flow characteristics become more robust, and the viscosity increases. From the point of view of the moving process and the measured fluidity, the slurry has better working performance and better cohesion when the cement-sand ratio is between $1 / 1.3-1 / 1.1$.

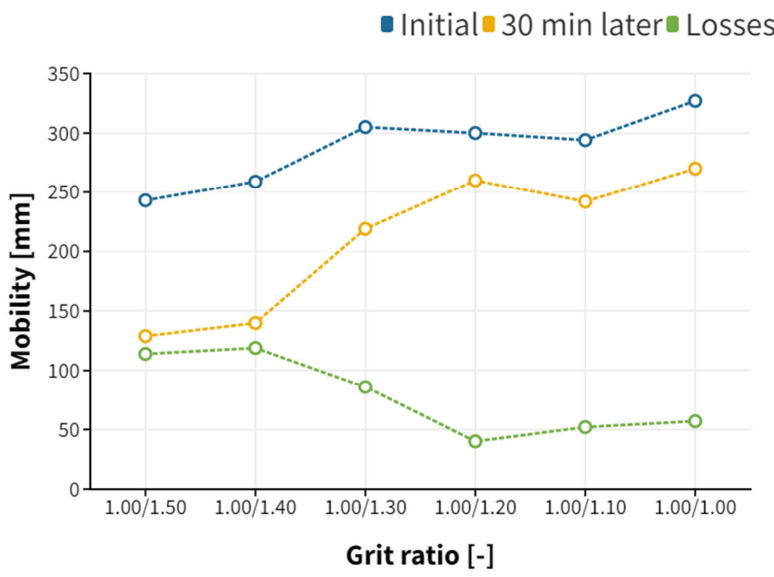

Fig. 1. Effect of sand to cement ratio on the flow of grout

The effect of the sand-cement ratio on slurry velocity is shown in Figure 1. The flow rate decreases with the increase of the sand-cement ratio (with the gradual decrease of the sand-cement ratio).

Table 3

Effect of cement to sand ratio on the strength of cementitious grout

\begin{tabular}{|c|c|c|c|c|c|c|c|}
\hline \multirow{4}{*}{ Items } & \multirow{2}{*}{$\begin{array}{c}\text { Grit } \\
\text { ratio }\end{array}$} & \multicolumn{2}{|c|}{ 1d strength } & \multicolumn{2}{c|}{ 3d strength } & \multicolumn{2}{c|}{ 28d strength } \\
\cline { 3 - 8 } & Flexural & $\begin{array}{c}\text { Pressure } \\
\text { resistance }\end{array}$ & Flexural & $\begin{array}{c}\text { Pressure } \\
\text { resistance }\end{array}$ & Flexural & $\begin{array}{c}\text { Pressure } \\
\text { resistance }\end{array}$ \\
\hline Unit & {$[-]$} & {$[\mathrm{MPa}]$} & {$[\mathrm{MPa}]$} & {$[\mathrm{MPa}]$} & {$[\mathrm{MPa}]$} & {$[\mathrm{MPa}]$} & {$[\mathrm{MPa}]$} \\
\hline \multirow{5}{*}{ Value } & $1 / 1.5$ & 5.1 & 22.3 & 10.4 & 49 & 12.2 & 60 \\
\cline { 2 - 8 } & $1 / 1.4$ & 5.2 & 26.6 & 10.1 & 51 & 11.9 & 64.2 \\
\cline { 2 - 8 } & $1 / 1.3$ & 6.0 & 32.3 & 9.9 & 55 & 11.3 & 69.6 \\
\cline { 2 - 8 } & $1 / 1.2$ & 6.6 & 31.4 & 10.6 & 52 & 12.3 & 68.2 \\
\cline { 2 - 8 } & $1 / 1.1$ & 6.4 & 30.7 & 10.2 & 51 & 12.0 & 67 \\
\cline { 2 - 8 } & $1 / 1$ & 4.3 & 16.2 & 10.2 & 47.7 & 9.4 & 57.2 \\
\hline
\end{tabular}

The effect of the cement-sand ratio on the strength of cement-based grout can be seen in Table 3. With the increase of cement-sand ratio, the compressive strength shows a larger trend in the middle and smaller at both ends. If the amount of sand is too much or the amount of cement is large, it will decrease the strength of the grout specimen. Because of the high strength of quartz sand, in the early strength test, most of the samples with a lime-sand ratio of $1 / 1.5$ are broken at the lime-sand interface. It also shows that the bonding force is insufficient, and more sand grains are in the cross-section. When the ratio of water, lime, and sand is small, the pores inside the slurry are increased with the decrease 
of cement paste. After the specimen with a water-cement-sand ratio of $1 / 1$ reaches the failure of the strength sample, most of the cracks have the surface of cement paste, which does not achieve the best filling effect. The change of slurry strength is small in the range of $1 / 1.3-1 / 1.1$, but the numerical value is higher, which has little effect on the strength. In other words, under the premise that the fineness modulus of quartz sand remains unchanged, the sand and cement match in this range, and the ideal filling effect is achieved. This is also in line with the most compact filling theory trend and the fitting curve of the lime-sand ratio.

The effect of sand to grout ratio on the strength of the grout can be seen in Figure 2, with the sand to grout ratio in the range of 1 to 1.5 gradually increased (with the gradual reduction of the sand to grout ratio), the grout strength then increased and then reduced the trend of change.

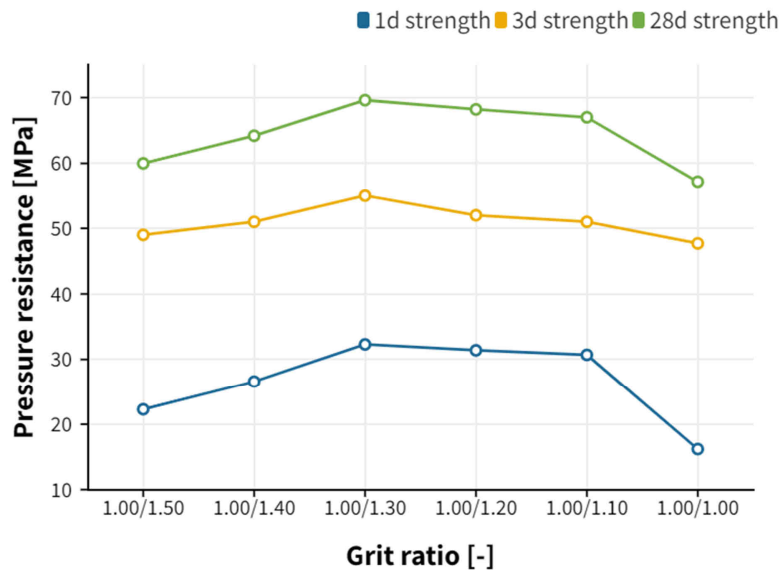

Fig. 2. Effect of sand to cement ratio on the compressive strength of the grout

We are following the technical requirements for cementitious materials in "cementitious grout" [18], which is a building material industry standard of the people's republic of China. When the naphthalene-formaldehyde superplasticiser is used, the water-cement ratio is 0.35 , and only the water-cement ratio is $1 / 1.2$ and $1 / 1.1$, the working performance and early strength of the slurry can be achieved, and the compressive strength can reach $68.2 \mathrm{MPa}$ in 28 days. However, it does not meet the technical requirements of "cementitious grout", which ask $70 \mathrm{MPa}$ a least. It can only be used in cement-based structural grouting materials with low strength, which is similar to the strength of $\mathrm{C} 60$ cement.

There are many factors affecting the shrinkage, mainly the cement variety, the variety of aggregates, the type and admixture amount, the matching ratio, and the maintenance conditions. The study focuses on the influence of the water-cement ratio and cement-sand ratio on the shrinkage performance of grout and considers how to improve its shrinkage performance and achieve the purpose of expansion by mixing with an expander.

The three sets of tests obtained in the above tests for changing the cement-sand ratio, were basically meets the flow and early strength requirements of cement-based grouting materials in "cementitious grout". Then they were subjected to shrinkage tests. 
Effect of cement-sand ratio on the shrinkage properties of grout

\begin{tabular}{|c|c|c|c|c|c|}
\hline \multirow{2}{*}{ Items } & $\begin{array}{c}\text { Grit } \\
\text { ratio }\end{array}$ & 3d systolic & 7d systolic & 14d systolic & 14d systolic \\
\hline Unit & {$[-]$} & {$[\mathbf{m m}]$} & {$[\mathbf{m m}]$} & {$[\mathbf{m m}]$} & {$[\mathbf{m m}]$} \\
\hline \multirow{3}{*}{ Value } & $1 / 1.2$ & -0.017 & -0.009 & -0.016 & -0.02 \\
\cline { 2 - 6 } & $1 / 1.1$ & -0.027 & -0.015 & -0.023 & -0.031 \\
\cline { 2 - 6 } & $1 / 1$ & -0.065 & -0.055 & -0.056 & -0.069 \\
\hline Conditions & - & $\begin{array}{c}\text { In-water } \\
\text { conservation }\end{array}$ & $\begin{array}{c}\text { In-water } \\
\text { conservation }\end{array}$ & $\begin{array}{c}\text { In-water } \\
\text { conservation }\end{array}$ & Aerial conservation \\
\hline
\end{tabular}

Performance indices of the grout at the optimum mix ratio

\begin{tabular}{|c|c|c|c|}
\hline \multicolumn{2}{|c|}{ Items } & Unit & Value \\
\hline \multirow{3}{*}{ Mobility } & Initial & {$[\mathrm{mm}]$} & 294 \\
\cline { 2 - 4 } & 30 min later & {$[\mathrm{mm}]$} & 242 \\
\cline { 2 - 4 } & Losses & {$[\mathrm{mm}]$} & 52 \\
\hline \multirow{2}{*}{$1 \mathrm{~d}$ strength } & Flexural & {$[\mathrm{MPa}]$} & 6.6 \\
\cline { 2 - 4 } & Pressure resistance & {$[\mathrm{MPa}]$} & 31.4 \\
\hline \multirow{2}{*}{$3 d$ strength } & Flexural & {$[\mathrm{MPa}]$} & 52 \\
\cline { 2 - 4 } & Pressure resistance & {$[\mathrm{MPa}]$} & 12.3 \\
\hline \multirow{2}{*}{$28 d$ strength } & Flexural & {$[\mathrm{MPa}]$} & 68.2 \\
\cline { 2 - 4 } & Pressure resistance & {$[\mathrm{MPa}]$} & 2214 \\
\hline \multicolumn{2}{|c|}{ Wet density } & {$[-]$} & -0.016 \\
\hline
\end{tabular}

Table 4 shows that the fastest stage of shrinkage occurs in the early stages and that the shrinkage values are smaller for $7 \mathrm{~d}$ than for $3 \mathrm{~d}$ of curing in water, indicating a micro-expansion effect. When placed in air for maintenance, the water loss is large, and the shrinkage is significant. The shrinkage values in the test increased with the increase in the cement to sand ratio, and the increase in the relative amount of cement in the grout would increase the shrinkage of the grout specimen. Curing in the air rises the shrinkage as the cement to sand ratio increases, indicating that shrinkage is more significant in the air than in water. Fixing in water reduces the shrinkage of the grout. Therefore the following shrinkage test specimens were cured in water. The shrinkage of the grouting material is minimised when the cement to sand ratio is $1 / 1.2$.

To sum up, when we use a $1.2 \%$ naphthalene superplasticiser, the water-cement ratio is 0.35 , and the cement-sand ratio is $1 / 1.2$. The slurry performance index of the best mix ratio is given in the following table.

\section{Effect of water-cement ratio on the workability and mechanical properties of structural grout}

The water-cement ratio refers to the weight ratio of the water in the slurry to the cementitious material. The change of the water-cement ratio will directly affect the strength of the slurry. When we increase the water consumption to improve the fluidity of the slurry, we need to ensure the stability and quality of the slurry. Otherwise, the working performance of the slurry will be destroyed. Therefore, the water-cement ratio cannot be determined by simple fluidity. It should also be considered according to the strength of the 
slurry. The working performance and mechanical properties of the slurry are weighed, and the water-cement ratio of the slurry is adjusted so that the slurry can reach an ideal state in both aspects [19]. The water-cement ratio is reduced from 0.35 to 0.29 , and the viscosity coefficient of the mortar rises. Small water-cement ratio, the amount of cement slurry is small, the sand cannot be suspended in which the yield shear stress is too large, resulting in mortar mixes do not have good fluidity. While the water-cement ratio is large, the amount of cement paste is large. It will produce delamination and separation because the yield shear stress is too small, so the water-cement ratio is also an essential factor affecting the flow of grout.

The study uses the grout's expansion degree and expansion speed to reflect the grout's flowability comprehensively. Expansion is closely related to shear stress $\tau_{0}$. When the grout falls and expands, it stops flowing when the gravity of the grout is not enough to overcome its shear stress. From a theological point of view, the expansion rate can also be a good reflection of the viscosity factor $\eta$ of the concrete mix. Therefore, by studying the influence of factors such as the water-cement ratio on the expansion degree and expansion speed of the mortar, it is possible to reflect the law of change in the rheological properties of the battery [20]. The amino water reducing agent AS which is well adapted to the $42.5 \mathrm{R}$ grade ordinary silicate cement used, was chosen for the test, improving the later strength, with dosing of $0.7 \%$ AS (cementitious material). The optimum cement-sand ratio was selected to be 1.2 in the range of $1 / 1.3$ to $1 / 1.1$, and the water-cement ratio was varied in the range of 0.29 to 0.35 until the flow rate could not meet the standard. When the water-cement ratio is 0.35 , the grout is difficult to be formed by separation, and the following test water-cement ratio is changed to 0.34 .

In Table 6, the initial flow rate of the grout and the flow rate after 30 min became smaller as the water-cement ratio decreased from 0.34 to 0.29 with other constant amounts, the flow rate loss became more prominent, and the bonding increased. The water reduction rate of AS is greater than that of NF, which effectively reduces the water consumption of the grout and ensures a significant flow rate at low water consumption. From the point of view of mixing and ease, the water-cement ratio is in the range of 0.3 to 0.33 , and the grout has better ease of mixing. When the water-cement ratio is too large, the water retention is not good, resulting in grout and micro-secretion segregation.AS is more compatible than NF with ordinary silicate cement, the water reduction rate is significant, and the grout's consistency is slight.

Table 6

Effect of water-cement ratio on the workability of the grout

\begin{tabular}{|c|c|c|c|c|c|c|}
\hline \multirow{2}{*}{ Items } & \multirow{2}{*}{$\begin{array}{c}\text { Water-glue } \\
\text { ratio }\end{array}$} & \multicolumn{3}{|c|}{ Fluidity } & \multirow{2}{*}{ Wet density } & \multirow{2}{*}{ Harmony } \\
\hline & & Initial & 30 min later & Losses & & \\
\hline Unit & {$[-]$} & {$[\mathrm{mm}]$} & {$[\mathrm{mm}]$} & {$[\mathrm{mm}]$} & {$\left[\mathrm{kg} / \mathrm{m}^{3}\right]$} & {$[-]$} \\
\hline \multirow{5}{*}{ Value } & 0.34 & 346 & 329 & 17 & 1886 & Lightly divorced \\
\hline & 0.33 & 326 & 320 & 6 & 1901 & Good \\
\hline & 0.31 & 301 & 291 & 10 & 1933 & Good \\
\hline & 0.30 & 299 & 264 & 35 & 1949 & Good \\
\hline & 0.29 & 235 & 163 & 72 & 2057 & Sticky \\
\hline
\end{tabular}

From Figure 3, we can clearly see that the initial flow, the flow after 30 minutes, and the loss flow after 30 minutes all change with the gradual increase of the water-cement ratio. However, the initial flow rate and the flow rate after 30 minutes increase with the rise of 
water-cement ratio, while the loss flow after 30 minutes decreases with the increase of water-cement ratio. Therefore, it can be known that the higher the water-cement ratio, the better the fluidity, the more the aggregate can be suspended in the slurry. It can improves the working performance of the mixture ratio.

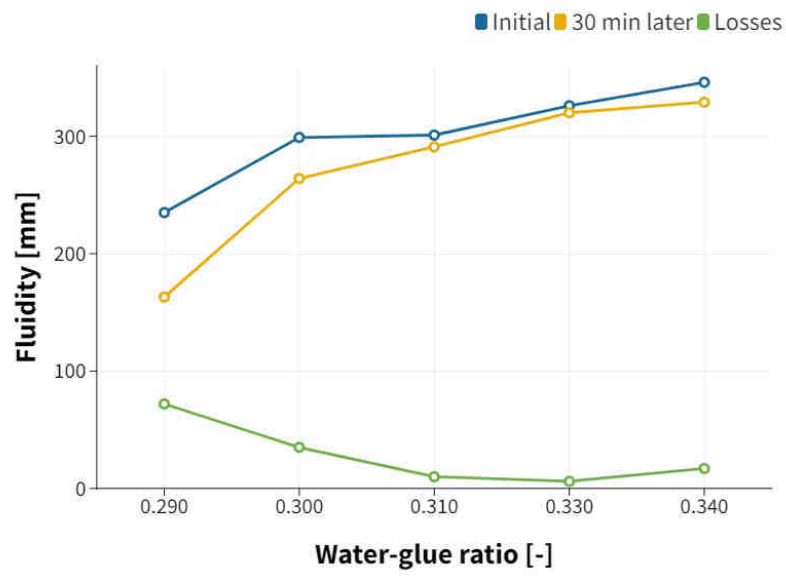

Fig. 3. Effect of water-cement ratio on the working properties of grout

The water-cement ratio is an essential factor in the variation of the strength of the grout. As seen in Table 7, the compressive strength of the grout is progressively more remarkable as the water-cement ratio decreases from 0.34 to 0.29 , with other quantities remaining constant. The water-cement ratio has a relatively significant effect on the initial strength, with a rather large increase in initial strength and a minor increase in compressive strength as time becomes longer. The trend of change in compressive strength is growing. The smaller the water-cement ratio, the greater the compressive strength.

Table 7

Effect of water-cement ratio on the strength of the grout

\begin{tabular}{|c|c|c|c|c|c|c|c|}
\hline \multirow{3}{*}{ Items } & \multirow{2}{*}{$\begin{array}{c}\text { Water-glue } \\
\text { ratio }\end{array}$} & \multicolumn{2}{|c|}{ 1d strength } & \multicolumn{2}{|c|}{ 3d strength } & \multicolumn{2}{c|}{ 28d strength } \\
\cline { 2 - 8 } & Flexural & $\begin{array}{c}\text { Pressure } \\
\text { resistance }\end{array}$ & Flexural & $\begin{array}{c}\text { Pressure } \\
\text { resistance }\end{array}$ & Flexural & $\begin{array}{c}\text { Pressure } \\
\text { resistance }\end{array}$ \\
\hline Unit & {$[-]$} & {$[\mathbf{M P a}]$} & {$[\mathbf{M P a}]$} & {$[\mathrm{MPa}]$} & {$[\mathbf{M P a}]$} & {$[\mathrm{MPa}]$} & {$[\mathrm{MPa}]$} \\
\hline \multirow{4}{*}{ Value } & 0.34 & 5.7 & 22.9 & 9.9 & 58.4 & 11.2 & 80.9 \\
\cline { 2 - 8 } & 0.33 & 5.3 & 24.2 & 10.1 & 60.7 & 11.2 & 83.2 \\
\cline { 2 - 8 } & 0.31 & 6.1 & 30.8 & 11.6 & 64.4 & 11.3 & 85.5 \\
\cline { 2 - 8 } & 0.30 & 6.4 & 35.3 & 14.1 & 66.9 & 13.6 & 87.1 \\
\cline { 2 - 8 } & 0.29 & 7 & 37.9 & 11.9 & 68.6 & 12.8 & 89.7 \\
\hline
\end{tabular}

The trend of the gradual decrease in compressive strength of the grout with increasing water-cement ratio at $1 \mathrm{~d}, 3 \mathrm{~d}$, and $28 \mathrm{~d}$ is derived from Figure 3 . The $1 \mathrm{~d}$ and $3 \mathrm{~d}$ strengths curve is more incredible, indicating a more remarkable decrease with increasing water-cement ratio. 


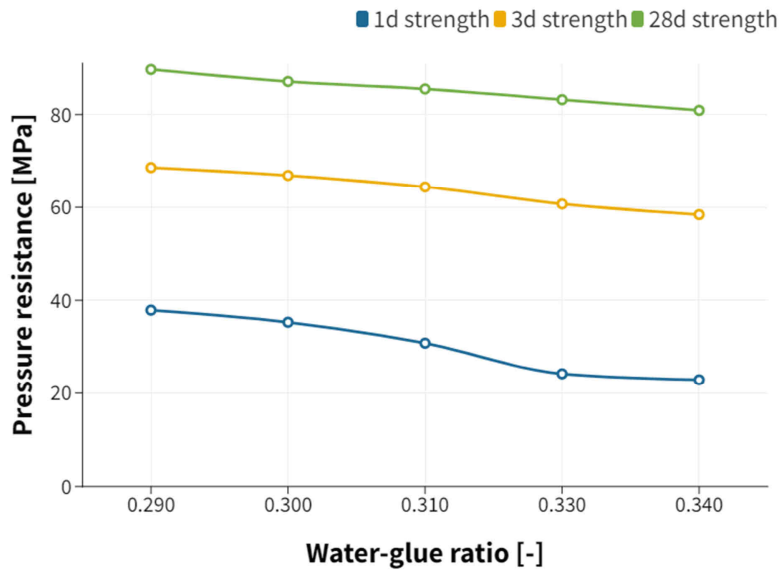

Fig. 4. Effect of water-cement ratio on the working properties of the grout

In summary, according to the technical requirements of "cementitious grout". Grout with a water-cement ratio between 0.3 and 0.33 meets the requirements for workability and strength, and a C80 grout can be formulated using AS. The early and late strength of the grout is improved compared to that of NF. As the water-cement ratio decreases, the flow rate decreases, the flow expansion loss becomes more significant, and the strength gradually increases. In terms of mixing and ease, the water-cement ratio is in the range of 0.3 to 0.33 , and the grout has better ease of mixing [21]. The intermediate three sets of tests meeting the flow and strength requirements of "cementitious grout" were then studied in shrinkage tests.

Table 8

Effect of water-cement ratio on the shrinkage properties of grout

\begin{tabular}{|c|c|c|c|c|}
\hline \multirow{2}{*}{ Items } & $\begin{array}{c}\text { Water-glue } \\
\text { ratio }\end{array}$ & 3d systolic value & 7d systolic value & 14d systolic value \\
\hline \multirow{2}{*}{ Unit } & {$[-]$} & {$[\mathbf{m m}]$} & {$[\mathbf{m m}]$} & {$[\mathbf{m m}]$} \\
\hline \multirow{3}{*}{ Value } & 0.33 & 0.020 & 0.015 & -0.035 \\
\cline { 2 - 5 } & 0.31 & 0.010 & 0.010 & -0.030 \\
\cline { 2 - 5 } & 0.30 & 0.040 & 0.030 & -0.015 \\
\hline Conditions & - & In-water conservation & In-water conservation & In-water conservation \\
\hline
\end{tabular}

In Table 8, we can see that in the early stage, the volume of slurry specimens expanded slightly under the action of AS to retain water (to avoid dry shrinkage caused by water loss). However, amino-sulphonate superplasticiser contains complex-forming groups $\left(-\mathrm{COOH},-\mathrm{OH},-\mathrm{NH}_{2}\right)$. With the progress of hydration, it forms an unstable complex with free $\mathrm{Ca}^{2+}$ in the alkaline medium of cement slurry, which will decompose itself and not affect the hydration, inhibiting the initial hydration of cement. With the increase of time, the shrinkage rate increases finally in a shrinkage state, the test with the water-cement ratio decreases, the shrinkage is also decreasing, the water-cement ratio of $0.3 \mathrm{AS}$ of the grout shrinkage is relatively tiny. 
With the increase of the admixture of expander, the flow degree decreases and the strength also decreases gradually, but the expansion of the specimen shows a growing trend. To achieve the requirements of the grout, we must coordinate the relationship between the working performance and mechanical properties to achieve a better effect of comparison and coordination. From the test results and the phenomenon and ease of view, to get each performance is better than the ratio. The amount of each component and the test performance index are shown in the Table 9.

Table 9

Performance index of grout at an optimum mix ratio

\begin{tabular}{|c|c|c|c|}
\hline \multicolumn{2}{|c|}{ Items } & Unit & Value \\
\hline \multirow{3}{*}{ Mobility } & Initial & {$[\mathrm{mm}]$} & 299 \\
\cline { 2 - 4 } & 30 min later & {$[\mathrm{mm}]$} & 264 \\
\cline { 2 - 4 } & Losses & {$[\mathrm{mm}]$} & 35 \\
\hline \multirow{2}{*}{$1 \mathrm{~d}$ strength } & Flexural & {$[\mathrm{MPa}]$} & 6.4 \\
\cline { 2 - 4 } & Pressure resistance & {$[\mathrm{MPa}]$} & 35.3 \\
\hline \multirow{2}{*}{$3 \mathrm{~d}$ strength } & Flexural & {$[\mathrm{MPa}]$} & 14.1 \\
\cline { 2 - 4 } & Pressure resistance & {$[\mathrm{MPa}]$} & 66.9 \\
\hline \multirow{2}{*}{$28 \mathrm{~d}$ strength } & Flexural & {$[\mathrm{MPa}]$} & 13.6 \\
\cline { 2 - 4 } & Pressure resistance & {$[\mathrm{MPa}]$} & 87.1 \\
\hline \multicolumn{2}{|c|}{ Wet density } & {$[\mathrm{mm}]$} & -0.015 \\
\hline \multicolumn{2}{|c|}{$14 d$ shrinkage(in-water conservation) } &
\end{tabular}

To sum up, when we use $0.7 \%$ amino-sulphonate superplasticiser (solid content $25 \%$ ), water-cement ratio 0.3 , sand ratio 1-1.2, all kinds of technical properties of high-performance cement-based structure slurry are the best.

\section{Conclusion}

1. In the range of $1 / 1.5-1 / 1.1$, the fluidity of the slurry increases with the increase of the lime-sand ratio, the flow loss decreases at first and then increases, and the viscosity also increases. From the point of view of the stirring process and the expansion of the flow, when the slurry is between $1 / 1.3-1 / 1.1$, it has good compatibility. The slurry is dense and stable and has adhesion. With the increase of the water-cement-sand ratio, the strength is more considerable in the middle and smaller at the end. If the amount of sand or cement is too much, the strength of the slurry specimen will decrease, and the shrinkage value will increase with the increase of the water-cement-sand ratio. The test results show that the optimum water-cement-sand ratio is $1 / 1.2$.

2. When the water-cement ratio is in the range of $0.34-0.29$, the fluidity of the slurry decreases with the increase of the water-cement ratio. At the same time, the liquidity loss increases, and the viscosity increases. According to the degree of base flow expansion in the mixing process, the compatibility between amino superplasticiser and slurry in the range of $0.3-0.33$ is good. The compressive strength of the slurry increases gradually, the water-cement ratio has a significant influence on the initial strength, and the addition of the initial strength is relatively large. With the extension of time, the increase of compressive strength becomes smaller, and the changing trend of total compressive strength increases. The smaller the water-cement ratio, the greater the compressive strength; as the water-cement ratio decreases, the shrinkage decreases. 
A comprehensive comparison of the water-cement ratio of 0.3 amino water-reducer grouting material has the best results in all tests.

\section{Acknowledgments}

Research Project of Chunhui Project of the Ministry of Education of the People's Republic of China (192641); Sichuan Provincial Education Department Project (500243T16046); Research on Risk Evaluation of Construction Engineering Projects from the Perspective of Incomplete Contracts; School-level Research Project of Chengdu Textile Higher Institute of Technology (500247X17007).

\section{References}

[1] Li VC, Horii H, Kabele P, Kanda T, Lim YM. Repair and retrofit with engineered cementitious composites. Eng Fract Mech. 2000;65:317-34. DOI: 10.1016/S0013-7944(99)00117-4.

[2] Cabrera JG, Al-Hasan AS. Performance properties of concrete repair materials. Constr Building Mater. 1997;11(5-6):283-90. DOI: 10.1016/S0950-0618(97)00049-4.

[3] Emmons PH, Vaysburd AM. System concept in design and construction of durable concrete repairs. Constr Building Mater. 1996;10(1):69-75. DOI: 10.1016/0950-0618(95)00065-8.

[4] Shuai G, Li Z, Zhang D, Elhefnawey M, Li L. On rough set theory on achieving high quality cable material production by green low carbon technology. Ecol Chem Eng S. 2021;28(1):49-59. DOI: 10.2478/eces-2021-0005.

[5] Zhong Z, Zhang X, Yang X. Benefit evaluation of energy-saving and emission reduction in construction industry based on rough set theory. Ecol Chem Eng S. 2021;28(1):61-73. DOI: 10.2478/eces-2021-0006.

[6] Smith, MD, Perry, RL. Borehole grouting: Field studies and thermal performance testing. ASHRAE Winter Meeting. Chicago: 2000. Available from: https://www.osti.gov/biblio/20002328-borehole-grouting-fieldstudies-thermal-performance-testing.

[7] James WJ, Marc AS, John HS. Fire Damage Evaluation for Residential and Commercial Buildings. Sixth Congress on Forensic Engineering. San Francisco: 2012. Available from: https://ascelibrary.org/doi/abs/10.1061/9780784412640.057.

[8] Jiang X, Lin A, Ma H, Li X, Li Y. Minimizing the thermal bridge through the columns in a refrigeration room. Appl Therm Eng. 2019;165:114565. DOI: 10.1016/j.applthermaleng.2019.114565.

[9] Zhang Y, Ma H, Zhao S. Assessment of hydropower sustainability: Review and modeling. J Clean Prod. 2021;321:128898. DOI: 10.1016/j.jclepro.2021.128898.

[10] Anagnostopoulos CA. Effect of different superplasticisers on the physical and mechanical properties of cement grouts. Constr Building Mater. 2014;50:162-8. DOI: 10.1016/j.conbuildmat.2013.09.050.

[11] Azadi MR, Taghichian A, Taheri A. Optimization of cement-based grouts using chemical additives. J Rock Mech Geotech Eng. 2017;9(4):623-57. DOI: 10.1016/j.jrmge.2016.11.013.

[12] Mahmood WI, Mohammed AS, Ghafor K. Viscosity, yield stress and compressive strength of cement-based grout modified with polymers. Results Materials. 2019;4:10043. DOI: 10.1016/j.rinma.2019.100043.

[13] Lin X, Pang H, Wei D, Lu M, Liao B. Effect of the cross-linker structure of cross-linked polycarboxylate superplasticizers on the behavior of cementitious mixtures. Colloid Surf A. 2020;608:125437. DOI: 10.1016/j.colsurfa.2020.125437.

[14] Ahmed Z, Mouldi KM, Michèle QK, Nicolas M. Developmental potentiality of insulating lightweight concrete based on cork and calcareous sand. J Adhes Sci Technol. 2016;30(9):1129882. DOI: 10.1080/01694243.2015.1129882.

[15] Zhang X, Zang C, Ma H, Wang Z. Study on removing calcium carbonate plug from near wellbore by high-power ultrasonic treatment. Ultrason Sonochem. 2020;62:104515. DOI: 10.1016/j.ultsonch.2019.03.006.

[16] Mo L, Sun W, Jiang S, Zhao X, Ma H, Liu B, et al. Removal of colloidal precipitation plugging with high-power ultrasound. Ultrason Sonochem. 2020;69:105259. DOI: 10.1016/j.ultsonch.2020.105259.

[17] Liu W, Ma H, Walsh A. Advance in photonic crystal solar cells. Renew Sust Energy Rev. 2019;116:109436. DOI: $10.1016 /$ j.rser.2019.109436.

[18] The Professional Standards Compilation Group of People' Republic of China (JC/T986-2005) Cementitious grouting material. China Standards Press. Beijing:2005. Available from: http://www.jianbiaoku.com/webarbs/book/54049/3831006.shtml. 
[19] Sołowski G, Konkol I, Cenian A. Perspectives of hydrogen production from corn wastes in Poland by means of dark fermentation. Ecol Chem Eng S. 2019;26(2):255-63. DOI: 10.1515/eces-2019-0031.

[20] Marszałek M, Kowalski Z, Makara A. The possibility of contamination of water-soil environment as a result of the use of pig slurry. Ecol Chem Eng S. 2019;26(2):313-30. DOI: 10.1515/eces-2019-0022.

[21] Wang X, Yu R, Shui Z, Song Q, Zhang Z. Mix design and characteristics evaluation of an eco-friendly ultra-high performance concrete incorporating recycled coral based materials. J Clean Prod. 2017;165:70-80. DOI: 10.1016/j.jclepro.2017.07.096. 